\title{
Design and Analysis of a HTS Vernier PM Machine
}

\author{
Jiangui Li, Student Member, IEEE, and K. T. Chau, Senior Member, IEEE
}

\begin{abstract}
This paper proposes a novel high-temperature superconductor (HTS) vernier permanent-magnet machine which can offer low-speed high-torque operation under line frequency. The key is to newly introduce the flux-modulation poles which modulate the high-speed rotating field in the stator to become the low-speed rotating field in the airgap. Also, the use of HTS armature windings can greatly reduce the power loss and improve the power density. By using the time-stepping finite element method, the machine performances are analyzed. Hence, the validity of the proposed machine is verified.
\end{abstract}

Index Terms-Finite element method, high-temperature superconductor, permanent magnet, vernier machine.

\section{INTRODUCTION}

$\mathbf{T}$ HE discovery of high-temperature superconductor (HTS) superconducting at temperatures above $77 \mathrm{~K}$ in 1986 has made the HTS machines less expensive and more practical. In general, there are three kinds of HTS machine topologies [1]: the air-core topology in which both of the stator and rotor irons are replaced by non-magnetic material (except the back iron); the rotor iron topology which involves the iron-core rotor and air-core stator; and the small airgap topology which has both iron-core rotor and iron-core stator.

In recent years, various HTS machines have been developed for various applications, such as aircraft propulsion [2], ship propulsion [3] and wind power generation [4]. However, these machines generally desire the HTS windings mounting on the rotor, which make the refrigeration complicated and difficult. Also, for those low-speed applications such as ship propulsion and wind power generation, the machine needs to operate at low frequency by using a variable-frequency converter or to scale the speeds by incorporating a mechanical gear [5]. The associated converter loss or gear loss and the additional cost are disadvantageous. In order to utilize the line frequency supply and eliminate the mechanical gear loss, the magnetic-geared permanent-magnet (PM) machine [6] and the vernier PM machine [7] have been developed for low-speed high-torque applications.

The vernier is an instrument introduced by Pierre Vernier in 1631, which uses two graduated scales (a main scale and a specially graduated scale) to enable reading a fraction of a division on the main scale. The vernier PM machine utilizes the vernier

Manuscript received October 18, 2009. First published April 05, 2010; current version published May 28, 2010. This work was supported by a Grant (Project HKU 7105/07E) from the Research Grants Council, Hong Kong Special Administrative Region, China.

The authors are with the Department of Electrical and Electronic Engineering, The University of Hong Kong, Hong Kong (e-mail: jgli@eee.hku.hk).

Color versions of one or more of the figures in this paper are available online at http://ieeexplore.ieee.org.

Digital Object Identifier 10.1109/TASC.2010.2041762 concept, based on different numbers of pole-pairs, to convert the high-speed rotating field in the stator to the low-speed rotating field in the rotor. It takes the definite advantage that it involves only one rotor, rather than two rotors in its magnetic-geared counterpart. Nevertheless, this vernier PM machine desires a double-stator structure with two airgaps, which is complicated and difficult to fabricate.

In this paper, a HTS vernier PM machine is proposed. It possesses a novel single-airgap structure, which is much simpler than its two-airgap counterpart. Also, it newly incorporates HTS windings mounted in the inner stator, which makes it much easier for refrigeration than other machines with the HTS windings mounting on the rotor. In Section II, the design and realization of the proposed machine will be discussed. Then, Section III will derive its mathematical model. Section IV will be devoted to using the time-stepping finite element method for machine analysis. Finally, conclusion will be drawn in Section V.

\section{MACHINE DESIGN}

\section{A. Machine Configuration}

Fig. 1 shows the proposed machine configuration which adopts an outer-rotor arrangement. There is neodymium iron boron PMs mounting on the inner surface of the outer rotor, and HTS armature windings locating in the inner part of the inner stator. Borrowing from the idea of flux modulation in the magnetic gear that the stationary ferromagnetic ring can modulate between the high-speed airgap flux and the low-speed airgap flux [8], the flux-modulation poles are newly introduced in the outer part of the inner stator. Hence, these flux-modulation poles function to modulate the high-speed rotating field in the inner part of the inner stator to become the low-speed rotating field in the airgap which in turn synchronously rotates with the PM outer rotor.

This configuration takes the definite advantages that it involves only one airgap, and the HTS windings are located in the inner stator. The corresponding assembly is shown in Fig. 2. In order to utilize the vernier effect, it needs to satisfy the following relationship:

$$
p_{r}=N_{s}-p_{s}
$$

where $N_{s}$ is the number of flux-modulation poles, $p_{r}$ is the number of rotor pole-pairs and $p_{s}$ is the number of HTS armature winding pole-pairs. Consequently, the high-to-low speed ratio $G_{r}$ is given by:

$$
G_{r}=\frac{\left|m p_{s}+k N_{s}\right|}{m p_{s}}
$$




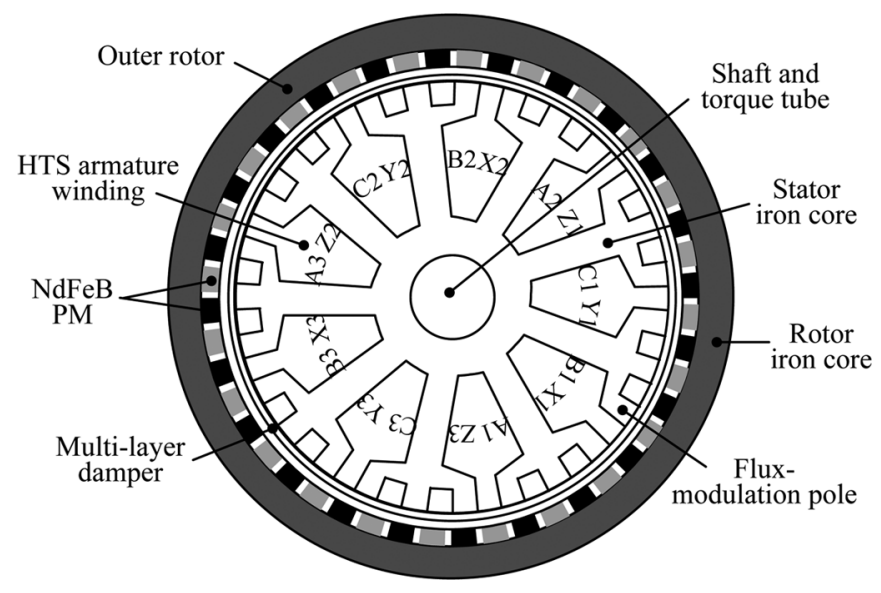

Fig. 1. Proposed machine configuration.

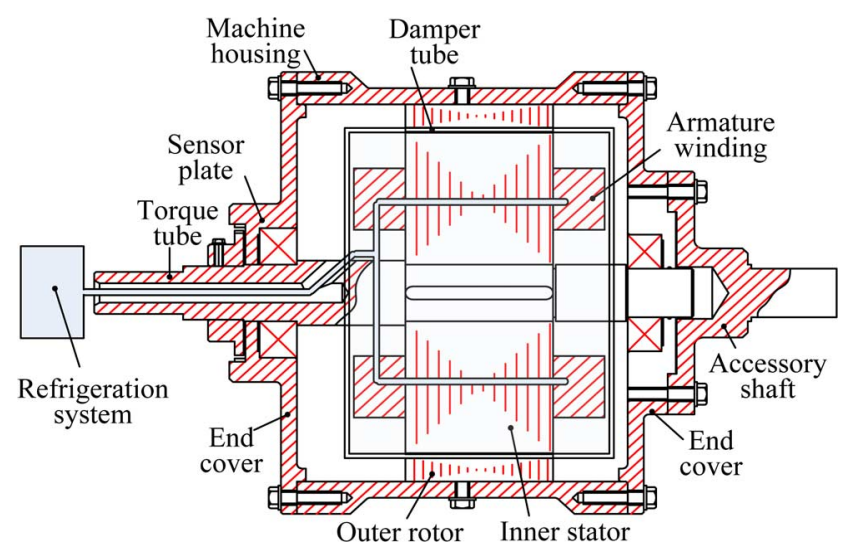

Fig. 2. Proposed machine assembly.

where $m=1,3, \cdots$ and $k=0, \pm 1, \pm 2, \cdots$. The combination of $m=1$ and $k=-1$ is selected since it yields the highest asynchronous space harmonic.

In this design, there are 9 slots in the inner stator, which are occupied by 3 -phase HTS armature windings with 6 poles $\left(p_{s}=\right.$ $3)$. Each stator tooth is split into 3 flux-modulation poles, thus constituting totally 27 flux-modulation poles $\left(N_{s}=27\right)$. From (1), $p_{r}=24$ is resulted, which denotes that there are $48 \mathrm{PM}$ poles mounting on the outer rotor. From (2), it yields $G_{r}=-8$ : 1 , where the minus sign indicates that the two rotating fields are with opposite directions. Therefore, when the line frequency is $50 \mathrm{~Hz}$ or $60 \mathrm{~Hz}$, the resulting rotating field in the stator is 1000 rpm or $1200 \mathrm{rpm}$ which is then modulated down to $125 \mathrm{rpm}$ or $150 \mathrm{rpm}$ rotating in an opposite direction, hence achieving lowspeed high-torque operation. The specifications of the proposed machine are listed in Table I.

\section{B. Machine Realization}

Since both the stator and rotor adopt the iron core (namely, the small airgap topology), the airgap length is minimized and the required ampere-turns are greatly reduced. This can be accomplished by using either warm iron or cold iron. The armature windings are based on the second generation yttrium barium copper oxide tapes [9]. It is composed of 8 racetrack yttrium
TABLE I

SPECIFICATIONS OF PROPOSED MACHINE

\begin{tabular}{lc}
\hline \hline No. of pole-pairs in rotor & 24 \\
No. of pole-pairs in stator & 3 \\
No. of flux-modulation poles & 27 \\
Rated frequency & $50 \mathrm{~Hz} / 60 \mathrm{~Hz}$ \\
Rated speed & $125 \mathrm{rpm} / 150 \mathrm{rpm}$ \\
Rated power & $350 \mathrm{~kW}$ \\
Outside diameter of outer rotor & $233 \mathrm{~cm}$ \\
Inside diameter of outer rotor & $201.1 \mathrm{~cm}$ \\
Length of airgap & $0.6 \mathrm{~cm}$ \\
Outside diameter of inner stator & $198 \mathrm{~cm}$ \\
Inside diameter of inner stator & $30 \mathrm{~cm}$ \\
Stack length & $40 \mathrm{~cm}$ \\
HTS material & Yttrium barium copper oxide \\
PM material & Neodymium iron boron \\
\hline \hline
\end{tabular}

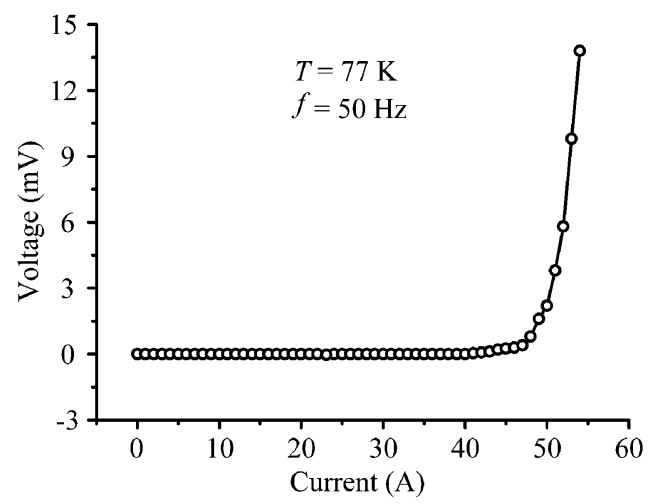

Fig. 3. Yttrium barium copper oxide critical current curve.

barium copper oxide coils. Since the yttrium barium copper oxide tape is quite brittle, stainless steel is usually needed to support it. A small gap is cut in the stainless steel to avoid a closed current loop. The corresponding critical current curve is shown in Fig. 3 which indicates that the resistance increases drastically when the current is above $51 \mathrm{~A}$. So, in this design, the rated current is set below this critical value.

The HTS winding is refrigerated by liquid nitrogen which is led in through cooling channels by pipes. The operating temperature is regulated at around $77 \mathrm{~K}$. The cooling channels are located between the small apertures around the yttrium barium copper oxide windings in the stator slot. The PMs are mounted on the inner surface of the outer rotor. If they are cooled to below $135 \mathrm{~K}$, their magnetization will no longer be uniaxial. Thus, in the proposed machine, a multi-layer damper tube is adopted to embrace the stator so that the PMs will not have direct contact with the liquid nitrogen. This damper tube also acts as a magnetic shield to alleviate the eddy-current loss in the neodymium iron boron PMs. Additionally, the damper tube can function to reduce the non-periodical vibration of the outer rotor, and to diminish the influence of the magnetic field generated by the outer rotor on the yttrium barium copper oxide armature windings in the inner stator.

Different from conventional machines that the driving torque is transmitted to the mechanical load via the shaft, the proposed machine employs a torque tube to transmit the driving torque. This torque tube has a thin wall which can effectively suppress the heat transfer between the machine and the surroundings. 


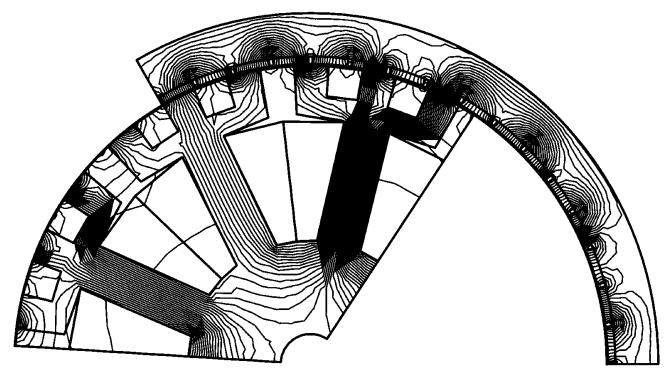

Fig. 4. Magnetic field distribution.

\section{MATHEMATICAL MODEL}

In order to perform the machine analysis, the formulation of machine model needs to assume that the working temperature is kept constant. Thus, the machine model can be expressed as the following electromagnetic field equation:

$$
\left\{\begin{array}{l}
\Omega: \frac{\partial}{\partial x}\left(v \frac{\partial A}{\partial x}\right)+\frac{\partial}{\partial x}\left(v \frac{\partial A}{\partial y}\right)=-J-v\left(\frac{\partial B_{r x}}{\partial x}-\frac{\partial B_{r x}}{\partial x}\right)+\sigma \frac{\partial A}{\partial t} \\
\mathrm{~S}_{1}: A=0
\end{array}\right.
$$

where $\Omega$ is the region of calculation, $A$ is the magnetic vector potential component along the $z$-axis, $J$ is the current density, $v$ is the reluctivity, $\sigma$ is the electrical conductivity, $B_{r x}$ and $B_{r y}$ are respectively the remnant flux density components of the PM along the $x$ and $y$ axes, and $\mathrm{S}_{1}$ is the boundary of the region of calculation.

According to the London equations, the electric field $E$ and magnetic field $B$ within the HTS material are governed by:

$$
\begin{aligned}
E & =\frac{\partial}{\partial t}\left(\frac{m}{n_{s} e^{2}} J_{s}\right)=\frac{\partial}{\partial t}\left(\Lambda J_{s}\right) \\
\nabla \times\left(\Lambda J_{s}\right) & =-B
\end{aligned}
$$

where $m$ is the electron mass, $e$ is the charge of an electron, $n_{s}$ is the super-electron density, and $J_{s}$ is the super-current density. Combining with the 4th Maxwell equation, it yields:

$$
\nabla^{2} B-\frac{\mu_{0}}{\Lambda} B=0
$$

Hence, the London penetration depth $\lambda_{L}$ can be deduced as:

$$
\lambda_{L}=\sqrt{\frac{\Lambda}{\mu_{0}}}
$$

which indicates that the magnetic field within the HTS material is exponentially suppressed. This depth is independent of frequency and is of the order of about 0.1 microns.

The maximum current that the HTS armature windings can carry with zero resistance is known as the critical current $I_{c}$. At the temperature $T=0 \mathrm{~K}, I_{c 0}=2 \pi r H_{c 0}$ where $r$ is the radius of the HTS wire and $H_{c 0}$ is the critical magnetizing field at $0 \mathrm{~K}$. When $T$ is above $0 \mathrm{~K}$ and below the critical temperature $T_{c}, I_{c}$ can be expressed as:

$$
I_{c}=I_{c 0}\left[1-\left(\frac{T}{T_{c}}\right)^{2}\right]
$$

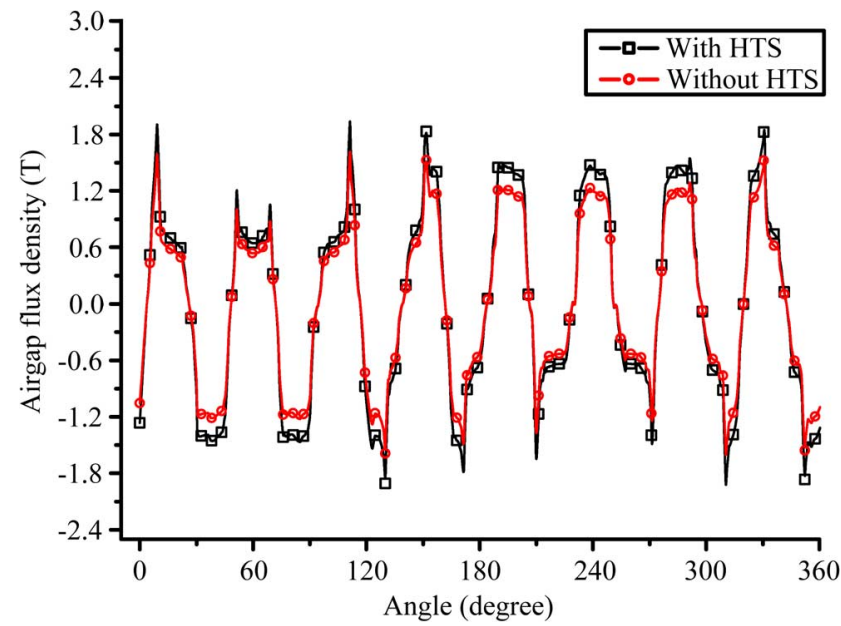

Fig. 5. Airgap flux density waveforms with and without HTS.

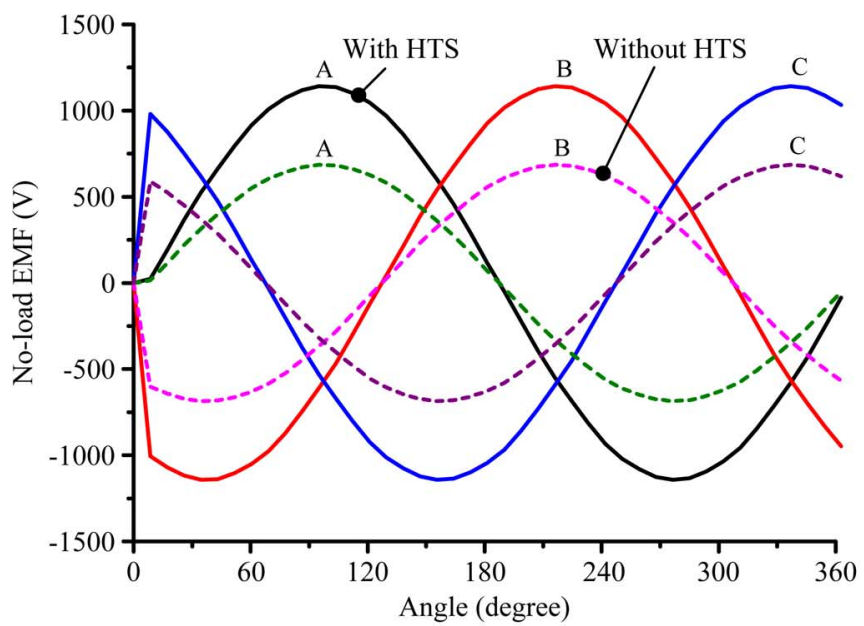

(a)

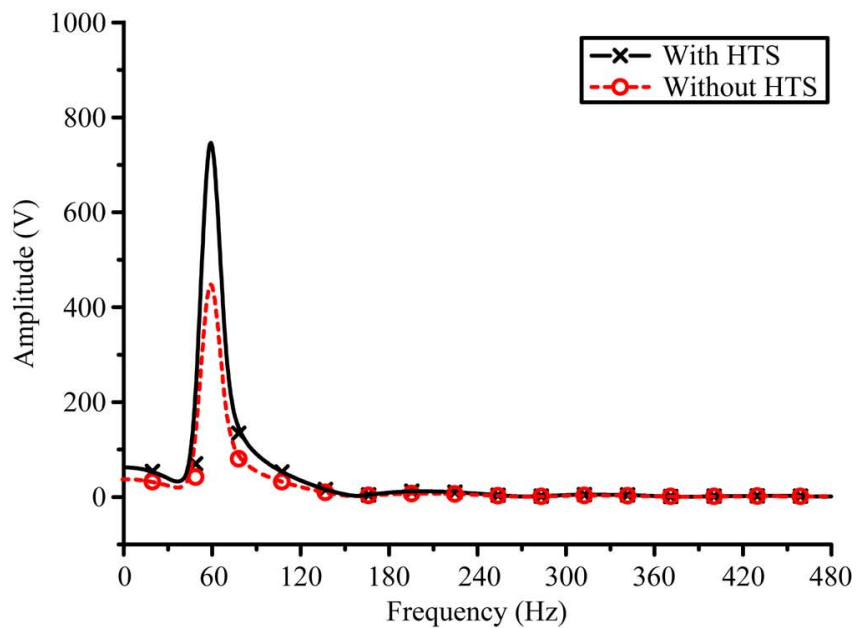

(b)

Fig. 6. No-load EMFs with and without HTS. (a) Waveforms. (b) Spectra.

Moreover, the dependency of the HTS armature winding resistivity $\rho$ on the current density $J$ for those values above the critical current density $J_{c}$ can be described as a power law: 


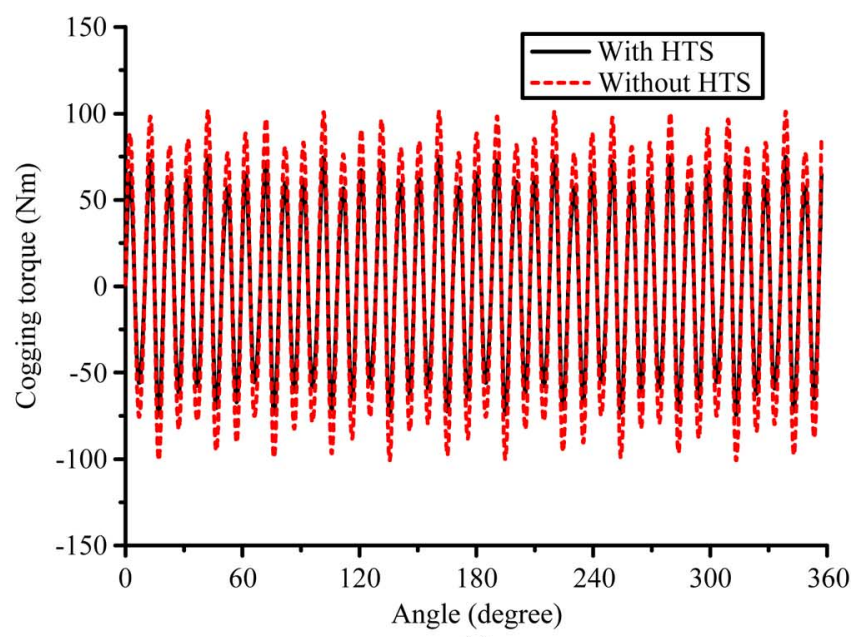

(a)

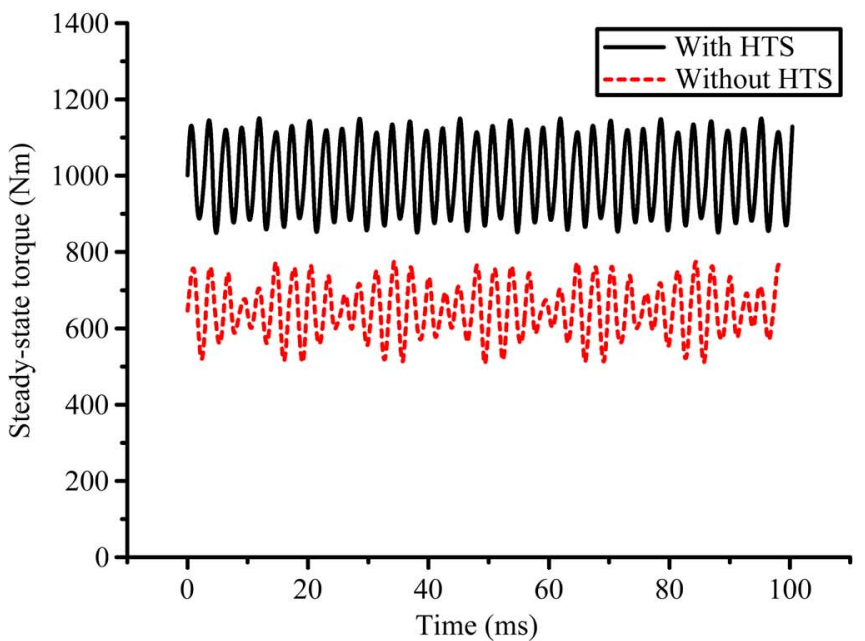

(b)

Fig. 7. Torque waveforms with and without HTS. (a) Cogging torque. (b) Steady-state torque.

$$
\rho=\rho_{0}\left(\frac{J}{J_{c}}\right)^{n}
$$

where $\rho_{0}$ is the electrical resistivity at $J_{c}$, and $n$ is the power law exponent. It should be noted that $n$ is not a constant, but decreases strongly with the applied current density.

\section{MACHINE ANALYSIS}

To verify the validity of the proposed machine, the performances of the proposed machine are analyzed by using the timestepping finite element method. Fig. 4 shows the magnetic field distribution. It can be observed that the flux lines per stator tooth pass through the flux-modulation poles separately, confirming the desired flux modulation.

In order to illustrate the merit due to the use of HTS windings, the proposed HTS vernier PM machine is compared with the conventional one. For fair comparison, they adopt the same configuration and are designed with the same output power.

Firstly, with and without using the HTS windings, the airgap flux density per stator pole-pair is shown in Fig. 5. As expected, the design with HTS can offer higher airgap flux density than that without HTS. Most importantly, it can be seen that there are 8 pole-pairs in the airgap within $120^{\circ}$ which actually corresponds to 1 pole-pair of stator rotating field. Hence, it further confirms that the proposed flux-modulation poles can successfully scale down the rotating field speed by 8 times.

Secondly, with and without using HTS windings, the no-load electromotive force (EMF) waveforms at $150 \mathrm{rpm}$ are shown in Fig. 6(a). The corresponding harmonic spectra are plotted in Fig. 6(b). It can be found that the EMF amplitudes are $1143 \mathrm{~V}$ and $685 \mathrm{~V}$ with and without using HTS, respectively, which denotes $167 \%$ improvement due to the use of HTS windings. Also, the harmonic spectra indicate that their fundamental frequency is at $60 \mathrm{~Hz}$ while their harmonic distortions are insignificant. This feature is attractive for direct-drive wind power generation since the wind turbine speed is rated at about $150 \mathrm{rpm}$ and the generated voltage is rated at $60 \mathrm{~Hz}$.

While the flux-modulation poles provide unique magnetic paths to modulate between the stator field and the rotor field, it makes different airgap lengths at different positions. Thus, the interaction between the flux-modulation poles and the rotor PMs causes the cogging torque. Fig. 7(a) shows the simulated cogging torque waveforms with and without using HTS. It can be found that the peak cogging torque is reduced from $99.8 \mathrm{Nm}$ to $76.4 \mathrm{Nm}$ with the use of HTS, which is actually due to the reduction of harmonic distortions. Meanwhile, Fig. 7(b) shows the steady-state torque waveforms with and without using HTS. As expected, the average steady-state torque is improved from $648 \mathrm{Nm}$ to $1002 \mathrm{Nm}$ with the use of HTS. It confirms that the normalized cogging torque is only about $7.6 \%$.

\section{CONCLUSION}

In this paper, a novel HTS vernier PM machine has been proposed for low-speed high-torque operation. This machine possesses a novel single-airgap structure which takes the definite advantages of simple and robust over the two-airgap vernier PM counterpart or two-rotor magnetic-geared counterpart. Also, the use of HTS armature windings can greatly reduce the power loss and improve the power density. Moreover, the use of outer-rotor arrangement with all HTS armature windings located in the inner stator can greatly ease the requirement of refrigeration. By using the time-stepping finite element method, the validity of the proposed machine has been verified. It also confirms that the use of HTS windings can significantly improve the generated EMF and steady-state torque as well as reduce the cogging torque. Therefore, the proposed machine is very promising for low-speed high-torque application such as ship propulsion and wind power generation.

\section{REFERENCES}

[1] B. Gamble, G. Snitchler, and S. S. Kalsi, "HTS generator topologies," in Proc. IEEE Power Eng. Soc. General Meeting, 2006, pp. 1-5.

[2] K. Sivasubramaniam, T. Zhang, M. Lokhandwalla, E. T. Laskaris, J. W. Bray, B. Gerstler, M. R. Shah, and J. P. Alexander, "Development of a high speed HTS generator for airborne applications," IEEE Trans. Appl. Supercond., vol. 19, no. 3, pp. 1656-1661, 2009.

[3] M. Frank, P. van Hasselt, P. Kummeth, P. Massek, W. Nick, H. Rothfischer, H. Schmidt, B. Wacker, H.-W. Neumuller, G. Nerowski, J. Frauenhofer, R. Hartig, and W. Rzadki, "High-temperature superconducting rotating machines for ship applications," IEEE Trans. Appl. Supercond., vol. 16, no. 2, pp. 1465-1468, 2006. 
[4] A. B. Abrahamsen, N. Mijatovic, E. Seiler, M. P. Sorensen, M. Koch, P. B. Norgard, N. F. Pedersen, C. Traeholt, N. H. Andersen, and J. Ostergard, "Design study of $10 \mathrm{~kW}$ superconducting generator for wind turbine applications," IEEE Trans. Appl. Supercond., vol. 19, no. 3, pp. 1678-1682, 2009.

[5] K. T. Chau, D. Zhang, J. Z. Jiang, C. Liu, and Y. J. Zhang, "Design of a magnetic-geared outer-rotor permanent-magnet brushless motor for electric vehicles," IEEE Trans. Magnetics, vol. 43, no. 6, pp. 2504-2506, 2007.

[6] L. Jian, K. T. Chau, and J. Z. Jiang, "A magnetic-geared outer-rotor permanent-magnet brushless machine for wind power generation," IEEE Trans. Industry Applications, vol. 45, no. 3, pp. 954-962, 2009.
[7] A. Toba and T. A. Lipo, "Novel dual-excitation permanent magnet vernier machine," in Conf. Rec. IEEE-IAS Annu. Meeting, 1999, pp. 2539-2544.

[8] K. T. Chau, D. Zhang, J. Z. Jiang, and L. Jian, "Transient analysis of coaxial magnetic gears using finite element comodeling," Journal of Applied Physics, vol. 103, no. 7, pp. 07F101:1-07F101:3, 2008.

[9] Y. Jiang, R. Pei, Z. Hong, Q. Jiang, and T. A. Coombs, "Design of an HTS motor," Journal of Physics: Conf. Series, vol. 97, pp. 12123:1-12123:6, 2008. 